\title{
Indisciplina na EREM Barão de Exu: Resolução de Conflito
}

\author{
Edilândia Carvalho de Sousa ${ }^{1}$; Maria de Lurdes Quaresma Dantas ${ }^{2}$; Rita Edevanira de Sá Carneiro ${ }^{3}$; \\ Maria Aparecida Oliveira Alves ${ }^{4}$
}

\begin{abstract}
Resumo: O presente estudo é um relato da experiência vivenciada na Escola de Referência em Ensino Médio Barão de Exu, Pernambuco, em 2013. Utilizou-se uma metodologia participativa envolvendo pais, alunos e corpo docente, com o uso de textos, questionários e vídeos com discussão. As sugestões das atividades foram propostas conjuntamente, bem como as estratégias para um maior envolvimento dos alunos e da própria família no processo ensino-aprendizagem. Dentre as reflexões propostas, a indisciplina foi a que mais mobilizou os sujeitos. Como resultados, uma série de intervenções foram sugeridas pelos envolvidos, para minimizar a indisciplina e as dificuldades de aprendizagem na escola. Concluiu-se que foi uma experiência importante, de grande participação espontânea por parte dos pais, bem como do envolvimento de todos, família, professores e dos próprios alunos em prol de uma educação com mais qualidade.
\end{abstract}

Palavras-Chave: indisciplina, Participação, Ensino-Aprendizagem.

\section{Indiscipline in the EREM Barão de Exu: Conflict Resolution}

\begin{abstract}
The present study is a report of lived experience in the School Reference in High School Barão de Exu, Pernambuco, by 2013. We used a participatory methodology involving parents, students and faculty, with the use of texts, videos and questionnaires and with discussion. The suggestions of activities were proposed jointly, as well as strategies for greater involvement of students and the whole family in the teaching-learning process. Among these reflections, indiscipline was the one that mobilized the individuals. As a result, a number of interventions were suggested by those involved, to minimize indiscipline and learning difficulties in school. We concluded thtat was an important experience, large spontaneous participation by parents as well as the involvement of everyone, family, teachers and students themselves towards a higher quality education .
\end{abstract}

Keywords: Discipline, Participation, Teaching and Learning.

\footnotetext{
${ }^{1}$ Graduada em Letras pela Universidade Regional do Cariri -URCA. Especialista em Língua Portuguesa pela mesma universidade e Especialista em Psicopedagogia Clínica e Institucional pela Faculdades Integradas do Vale do Ivaí -UNIVALE. Mestranda em Ciências da Educação pela Universidade Lusófona de Humanidades e Tecnologias, Lisboa/PT.

E-mail: edilandia1107@hotmail.com

${ }^{2}$ Pedagoga, Mestre em Ciências da Educação Pela Universidade San Carlos - Assunción - PY. E-mail: lurdes.2011.sh@ hotmail.com;

${ }^{3}$ Graduada em Ciências Biológicas pela Universidade Regional do Cariri -URCA. Especialista em Gestão Escolar e em Mídias na Educação ppela Universidade Federal do Ceará -UFC. E-mail: edevanira@ yahoo.com.br

${ }^{4}$ Graduada em Pedagogia pela Universidade Regional do cariri - URCA; Pós-Graduada em Educação Inclusiva pela Faculdades Integradas de Patos - FIP; Especialista em Políticas Educativas e Docência do Ensino Superior pela Fac. Formação de Professores de Araripina; Mestranda em Ciências da Educação pela Universidade Lusófona de Humanidades e Tecnologias, Lisboa/PT.

E-mail: aparecidaalves2011@ hotmail.com
} 


\section{Introdução}

"Disciplina é limite na medida certa"

(TIBA,1996)

Este artigo nasceu da experiência vivenciada na Escola de Referência em Ensino Médio Barão de Exu(EREM- Barão de Exu), no ano letivo de 2013 , tudo começou após a leitura dos resultados do primeiro bimestre do ano corrente e que foram detectados os baixos índices dos alunos ditos indisciplinados pelos professores.

Depois desta leitura dos dados a coordenação pedagógica resolve propor momento de reflexão sobre indisciplina com os professores, Tomado por base material doado à escola que continha proposta de trabalho para formação continuada dos professores.

A metodologia deu se da seguinte forma, apresentado o vídeo - Indisciplina na escola (GARCIA,2013).; slide de reflexão; leitura do texto de Parolin(2013) e questionário objetivo sobre a reflexão da prática docente em sala de aula.

$\mathrm{Na}$ segunda atividade para entender o que é indisciplina dentro da EREM- Barão de Exu foi realizado uma reunião de mestres com os pais dos alunos ditos indisplinados.

Convidamos os pais a participarem de uma reunião de pais mestres realizada no dia 11 de Junho de 2013, para fazer uma demonstração do mapa situacional do rendimento escolar do I Bimestre do ano letivo 2013, visto que foi percebido pelos professores e gestão, em reunião pedagógica, que o índice de rendimento escolar abaixo da média estava nas turmas de maior índice de ordem indisciplinar.

Os pais que participaram da reunião são pais de alunos que estão com rendimento baixo e com problemas de ordem disciplinar. A reunião teve um caráter mais observador e de apresentar propostas de intervenções possíveis, em casa, que ajudariam aos pais a ajudarem seus filhos e consequentemente ajudarão a escola no âmbito da aprendizagem e da disciplina escolar.

As sugestões apresentadas foram simples, mas que pareceram está esquecidas e que resolvemos reavivar aos pais para dar ênfase as suas atribuições como ser importante no processo de formação de seus filhos.

No intuito de entender o papel da família no processo de ensino e aprendizagem e traçar estratégias futuras que possibilitem maior êxito de nossos alunos, foi aplicado um questionário aos pais presentes na reunião e que vamos apresentar como uma visão da família sobre o processo de ensino aprendizagem e a disciplina na escola. 
Propor reflexão sobre indisciplina é antes de tudo entender o que é indisciplina para nossos alunos. Também aplicamos questionários aos alunos para compreender o que os alunos pensam sobre disciplina na escola.

Tivemos o cuidado de mapear algumas frases por eles citadas que apresentaremos para dá maior ênfase na nossa pesquisa e mostrar o pensamento real dos indivíduos que estamos formando.

Também é dá a corresponsabilidade das intervenções que serão fomentadas, de acordo com as sugestões dos mesmos e de toda a comunidade escolar.

\section{INdisciplina: Reflexão da prática docente em sala de aula.}

Após a reunião e aplicação dos questionários e anotações da coordenadora pedagógica para intervenções e compreensão dos fatores geradores de indisciplina pudemos detectar diferentes causas antes percebidas, de ordem interna e externa do âmbito escolar.

Foram pontuadas causas de indisciplina de origem externa da escola, em primeiro lugar a influencia da mídia e em segundo lugar as relações familiares. Como causas de origem interna da escola, em primeiro lugar foi o perfil dos alunos para uma escola de ensino de referência que é exigido um perfil de estudante profissional; no segundo lugar a qualidade do currículo - adequar para um currículo regional e conteúdos mais específicos para sua realidade; em terceiro lugar e que afeta as partes físicas e psicológicas dos alunos é o ambiente, caracterizando as salas de aula como inadequados ao número de alunos e a climatização, pois vivemos num clima muito quente.

\section{A afetividade interfere na disciplina de sala de aula.}

Sabemos que a afetividade é um elemento importante dentro de todo processo de ensinoaprendizagem, e não é diferente para manter a disciplina em sala de aula. Na terceira questão do estudo, abordado sobre o respeito aos professores que os alunos consideram "bons" e "amigos", os professores apontam como algo que faz parte do ser humano, e acreditam que o respeito acontece pelo elo de afetividade, possibilitando maior facilidade em aprender, e que esse elo também se estenderá à escola, vendo como um lugar seguro.

A indisciplina desperta sentimentos de ausência de limites, insegurança, medo, frustração, baixa autoestima, indignação, sentimento de incapacidade, são esses sentimentos negativos que fazem o professor estagnar diante dos desafios de manter a disciplina em sala de aula. 


\section{O desafio do gestor de sala de aula para manter uma boa disciplina e favorecer a aprendizagem.}

São muitos os desafios de um gestor de sala de aula, a disciplina, o conteúdo, a afetividade, o ensino, a aprendizagem, como conciliar tudo isso para manter uma boa disciplina e favorecer a aprendizagem?

Os trabalhos realizados pela equipe docente dessa instituição de ensino visa envolver os alunos em todo processo de ensino e aprendizagem com aulas mais atrativas que se aproximem dos interesses de seus alunos; Conscientização através de conversas em sala de aula com os alunos sobre a importância do estudo na melhoria e qualidade de vida. Busca envolver os alunos no processo dandoos corresponsabilidades, estimulam o protagonismo juvenil e autonomia individual e coletiva. Mas diante das reflexões que fizeram durante o momento de estudo, a formação continuada, chegaram à decisão de formalização do contrato de convivência.

Entenderam que a indisciplina depende de atitudes do educador, focando no que aconteceu no momento- sem considerar o passado, preservando as pessoas envolvidas para melhorar as relações e ter atitudes resolutivas, tendo expectativas futuristas e evitando conflitos. Também decidiram criar oportunidades para o aluno falar sobre a escola, criando assembleias em sala de aula para resoluções de problemas, sensibilizando os alunos para disciplina porque vale a pena estudar.

\section{INdisciplina: Uma visão da família}

O questionário aplicado foi idealizado pela equipe pedagógica e pelas técnicas educacionais, com aval da gestora. Foi distribuído canetas e o questionário a 20 pais e solicitado que respondessem no momento da reunião. Obtivemos apenas a devolução 06 questionários e várias desculpas para não se comprometerem com suas respostas, não cabendo aqui explanar sobre suas desculpas esfarrapadas e seus descompromissos com a escola e consequentemente com seus filhos.

Os pais responderam que o seu papel no processo de ensino e aprendizagem consiste em está atentos ao material escolar, fardamento, acordar os filhos para irem à escola, participar de reuniões, e orientá-los para o bom comportamento em sala de aula, prestar atenção à explicação dos professores e a obedecê-los.

A participação dos pais em momentos de estudos e suas contribuições foram bastante deficitárias, a maioria dos pais não acompanham seus filhos, os filhos não tem horário para estudos complementares, e mesmo os pais que dizem cobrar as atividades é percebido em suas falas que apenas cobram, não utilizam quaisquer ferramenta que possam estimular os estudos, ou estimulá-los 
pelo exemplo. Apontam o tempo como empecilho a participarem da vida escolar de seus filhos, a maioria dos pais trabalha fora.

Conhecendo as possibilidades de trabalho do município e das fichas cadastrais dos alunos dessa escola, onde é preenchido o tipo de atividade exercida pelos pais dos alunos, isso é apenas uma desculpa, pois a maioria dos trabalhadores do município trabalham no comercio ou repartições publicas que tem horário até às 18:00, ou ainda são agricultores que também a noite estão em casa.

Ao serem questionados sobre o que eles poderiam fazem em casa que poderiam ajudar na disciplina da escola, as respostas foram vagas, nenhuma das respostas tinha algo conciso, em senso comum apenas a conversação, e teve um pai que culpa a tecnologia pela indisciplina da filha na escola, "Conseguir tirá-la do face, todo problema de baixo rendimento escolar chama-se computados"(Pai, 03).

Na Questão 04:O que é indisciplina para você em sala de aula? Os três responsaveis dizem que a indisciplina é o desrespeito ao professor e aos colegas, 02 deixaram em branco e um culpa o professor pela falta de autoridade dentro de sala de aula e pelas aulas que não prendem a atenção dos alunos.

Com relação aos fatores geradores de indisciplina em uma sala de aula, três pais não responderam por não conhecerem a realidade do mundo escolar e preferiram deixar em branco, essa foi a desculpa dada. Os pais que responderam sobre o assunto foram enfáticos e conhecedores do mundo escolar, um pai aponta as conversas paralelas e o uso do celular, e os outros pesquisados apontam a família com um dos fatores geradores da indisciplina na sala de aula , pois "Geralmente tem problemas em casa com os pais"(Pai, 02).

Solicitamos sugestões para melhorar a disciplina na sala de aula, aqui vamos transcrever suas falas para ser questionadas pelo leitor, e logo retomadas nas considerações finais.

- “até onde eu sei está muito bom” (Pai, 05).

- "Professores, façam com que eles preste atenção na sala de aula, cobrem deles o melhor" (Pai, 04).

- "Criar um método para o aluno não entrar na escola com celular" (Pai, 03).

- "Incentivar o aluno a se desligar um pouco do computador e facebook”(Pai, 03).

- "Mais reuniões com os pais, cobrando mais da gente, porque não sabemos o que se passa na escola"(Pai, 01).

- "E ter mais diálogos" (Pai, 02).

Deixamos aqui para reflexões do leitor a transcrição das falas dos pais, mas uma fala que não estava nos questionários e nos deixou pensativos e bastante reflexivos com a nossa prática pedagógica foi dita por uma mãe que devolveu o questionário em branco vale a pena ser escrita para mais uma 
reflexão: "Não vou responder por que eu já pedir a ordem sobre minha filha, nada do que eu disser vai valer a pena ser dito", entregou o papel respirou fundo e abaixou a cabeça.

Vemos aqui um caso de omissão e um fator gerador de indisciplina na escola.

É possível que a indisciplina esteja revelando que a família possa, de alguma forma ter falhado no cumprimento de suas responsabilidades sociais. E que, uma dessas falhas seja a falta de estruturação moral das crianças sob sua guarda, que se manifesta na sala de aula como falta de limites, desrespeito, rebeldia e indiferença para com o professor.

\section{INdisciplina: A visão dos alunos}

Após aplicação dos questionários obtivemos algumas frases escritas pelos alunos que são os seus pensamentos, as visões da realidade vivida dentro dos muros escolares e fora deles. Vejamos algumas frases para nossa reflexão:

\footnotetext{
"Ser mal comportado e dá trabalho" aluno da turma do $1^{\circ} \mathrm{B}$

"É uma pessoa com falta de educação" Matheus - $1^{\circ} \mathrm{B}$

"Uma pessoa que não tem interesse em nada" Pedro - $1^{\circ} \mathrm{B}$

"É conteúdo dado e não explicado" Ramom - $1^{\circ} \mathrm{B}$

"É não respeitar uma regra que alguém lhe pede para fazer. Fazer destrato de uma regra" Philipe - $1^{\circ} \mathrm{B}$

"Uma pessoa que lida com as coisas tudo na brincadeira, que não quer nada da vida" Daiane $-1^{\circ} \mathrm{B}$

"É a falta de interesse, falta de respeito, o mau comportamento, a falta de colaboração, a conversa..." Suiane - $1^{\circ} \mathrm{B}$

"É saber das regras e não segui-las, não ter respeito com o colega e com o professor" Edivânia- $1^{\circ} \mathrm{E}$

"É quando as pessoas não respeitam as regras" Paula Beatriz - $1^{\circ} \mathrm{E}$

"Falta de comportamento é irresponsabilidade" Jualiane $-1^{\circ} \mathrm{E}$
}

Após verificarmos as frases, a cima, podemos condensar que a indisciplina na visão dos alunos é vista da seguinte forma: É a falta de respeito, a falta de educação, o mal comportamentos, a irresponsabilidade, ou simplesmente uma FALTA DE REGRAS.

Os nossos alunos estão pedindo regras, afinal, viver em sociedade é viver permeado por regras onde todos devem cumprir e o descumprimento delas acarretará punições. 


\section{Fatores gerados de indisciplina na sala de aula}

Para nossos alunos alguns fatores geram a indisciplina e comprovam através de suas palavras que indisciplina é o desrespeito as regras, como na fala de Edivania- $1^{\circ} \mathrm{E}$, quando questionada sobre indisciplina na sua sala de aula "“Algumas regras não são cumpridas”.

O que gera a indisciplina na sala de aula segundo os alunos pesquisados são:

- As conversas paralelas;

- Brincadeiras fora de hora;

- Desrespeito ao professor (a) e ao colega;

- O uso de celulares;

- A não entrega das atividades;

- Alunos desinteressados que atrapalham a aula;

- É o conteúdo dado e não explicado.

Os resultados acima é uma panorâmica do nosso mundo real, trazidos a tona para juntos intervirmos, e melhorarmos a convivência social do grupo escolar.

\section{O que deve ser feito em sala de aula segundo os alunos}

Apresentamos a seguir as propostas de intervenções segundo os alunos, que ao seu modo, dentro de seus conhecimentos e realidades, algumas propostas até severas demais que distorcem a boa pedagogia, mas vejamos:

- Professores mais legais;

- Expulsar o aluno bagunceiro;

- Conversar com o aluno;

- Punir os alunos com trabalhos individuais;

- Fazer com que os alunos gostem mais de estudar;

- O uso de tecnologia em sala de aula.

O que vimos acima são resultados da pesquisa e que os próprios alunos propõem como intervenção, mas há alunos que foram mais abrangentes em suas respostas e que temos que citá-los para dá responsabilidade a quem deve ter no processo de ensino-aprendizagem. "Primeiramente tem que haver diálogo, depois ocupar esses alunos com atividades escolares que motivem eles e que os 
pais façam parte também" (Claudione $-1^{\circ} \mathrm{E}$ ). Estão os alunos solicitando a participação dos pais neste processo?

Outros veem nos chamar a atenção para a corresponsabilidade dos alunos, chamando os para participar do processo, "Os professores mostrarem confiança neles que quando bagunçarem se sentirão culpados" (Ramon- $\left.1^{\circ} \mathrm{E}\right)$.

$\mathrm{Na}$ fala seguinte é reconhecido as intervenções da escola, "pra falar a verdade eu já nem sei, pois já conversaram e mostraram o certo para os alunos, mas sempre eles voltam a ser mal educados" (Wilton- $\left.1^{\circ} \mathrm{E}\right)$.

Há também propostas de alunos que condizem com a proposta do autor Joe Garcia,que foi trabalho com os professores, que é "Fazer com que os alunos gostem mais de estudar"(Lícia $\left.-1^{\circ} \mathrm{B}\right)$.

Cabe agora refletir sobre todo processo de ensino e aprendizagem, papeis dentro do contexto e das responsabilidade de cada agente para melhorar a indisciplina na escola, questionando se disciplina se aprende na escola.

\section{Considerações finais.}

Consideremos que disciplina na escola é fundamental para que o ensino e a aprendizagem sejam satisfatórios para ambos os agentes do processo.

Quando o In vem antes da disciplina , "O que atrapalha a disciplina é a intromissão do 'in'!'(PAROLIN,2005) percebemos que o IN é muito mais que um prefixo, é um indexador de muitas outras palavras que estão por trás do professor, aluno e família.

Ao professor o IN pode significar a indefinição do papel social do professor, que assume vários papeis para conseguir fazer o que lhe devido, ENSINAR.

Aos alunos o IN pode significar o interesse, pois esquecem que na vida o grande processo é crescer academicamente, profissionalmente, humanamente e porque não dizer espiritualmente. Essa visão restrita da vida os fazem não aproveitar os momentos de aprendizagem, e fazer o que tem que ser feito, APRENDER A FAZER, APRENDER A CONVIVER, APRENDER A SER, APRENDER A CONHECER, coisas que se aprende e praticam na escola para colocar na vida.

Aos Pais o IN pode significar a indisponibilidade para fazer o que tem que ser feito, EDUCAR.

Os filhos desses pais INdisponiveis e nossos alunos estão pedindo regras, afinal, viver em sociedade é viver permeado por regras onde todos devem cumprir e o descumprimento delas acarretará punições. 
Nossos alunos estão acostumados punições onde as regras são descumpridas, assim é a vida, mas não é o mundo escolar. Afinal, na escola estão em treinamento, e em treinamento não há punições, há repetições e isso faz com os nossos alunos tirem o foco. Esquecem que uma máxima: Se a lição se repete é porque você ainda não aprendeu. Nossos alunos estão acostumados a uma pedagogia punitiva, enquanto em formações os professores falam de pedagogia do amor ( CHALITA,2003), Educação Planetária ( MORIN,2000), eles não estão entendo o que a escola ensina e o que a vida cobra, isso gera indisciplina.

A escola é cheia de regras que devem se cumpridas, mas o seu descumprimento não gera punições como é esperado pelos alunos, afinal, se é treinamento para vida como entender o que é ensinado nos muros escolares e o que será cobrado da vida? Para eles há uma dissociação do que é dito e do que é feito.

Dado as reflexões para compreender o que é indisciplina na EREM Barão de Exu, nas visões de alunos, professores e família, coube a coordenação pedagógica a reflexão e a intervenção para melhoria do ambiente escolar e promover o ensino e aprendizagem.

Percebemos que quando questionados sobre a construção coletiva de normas e regras os professores, assim como os alunos, ficaram se questionando o que se pode fazer a mais, e pontuaram novas estratégias usadas. Mas em comum acordo sugerem um contrato "social" para toda escola, que deverá abranger todos os alunos matriculados na unidade de ensino.

Daí nasceu à ideia da construção de um contrato de convivência e regras para escola, pois seria permitida a participação dos alunos neste documento e assim no ano de 2013 foi construído coletivamente normas para melhoria da aprendizagem e do ensino na escola.

Como se constrói um contrato de trabalho em sala de aula? Esclarecendo os objetivos da aula, criando com os alunos regras de bom convívio e de trabalho, garantindo o respeito às individualidades e a participação de todos, em um ambiente propício à aprendizagem.

Aos alunos que não conseguem cumprir com o que eles mesmos contrataram só resta sofrerem sanções, que, aliás, devem estar previstas no contrato (PAROLIN,2005).

Visto que a construção do contrato de convivência obteve bons resultados na disciplina escolar, esta prática foi realizada logo no inicio de 2014. Segundo a coordenação pedagógica, neste ano letivo a indisciplina dentro do âmbito escolar não está tão ressaltada aos olhos como no ano anterior. Há casos isolados que estão sendo tratados individualmente como a participação da família, que são chamados à escola para tomar ciência do caso e chegar juntos, escola e família, a um denominador comum.

Acreditamos que chamar o aluno a responsabilidade e informar a família é dá sentido as regras para atingirmos o objetivo maior da escola, ENSINAR e do aluno, APRENDER. 
A educação tem por objetivo introduzir o aluno na prática de pensar sobre o ensinamento que lhe é passado em sala de aula e como ele é passado, além de dotálo de uma visão crítica dos conteúdos que aprende. Para isso, a rigidez metodológica cai por terra, uma vez que o aluno adquire o hábito de sempre refletir sobre o que é instituído, sem seguir cegamente o que lhe ensinam, mas sem ferir os objetivos comuns da educação. Neste sentido, a disciplina se torna relativa e o aluno tem a responsabilidade de eleger para si as regras que precisa seguir e de questionar porque se deve ser "disciplinado". Resumindo, quando uma regra não faz sentido corre-se o risco de o sujeito não a seguir, o que acarreta para o indivíduo o rótulo de "indisciplinado".(BOARINI, 1998, p. 14 Apud SILVA 2001).

Permear de sentido o fazer pedagógico é ensinar sentido para vida, é fazer o aluno compreender o processo e ensino e aprendizagem, é ensiná-lo a escolher as regras que deve seguir e que o formarão com SER.

\section{Referências}

CHALITA, Gabriel. Pedagogia do amor: a contribuição das histórias universais para formação de valores das novas gerações. São Paulo: Editora Gente,2003.

DELORS, Jacques (Coord.). Os quatro pilares da educação. In: Educação: um tesouro a descobrir. São Paulo: Cortezo. p. 89-102.

GARCIA, Joe. Indiciplina na escola. IN Série Gestor Escolar - Resolução de Conflitos. São Paulo: Edições SM, 2013.

MORIN, Edgar. Os sete saberes necessários à educação do futuro. São Paulo/Brasília: Cortes/UNESCO, 2000.

PAROLIN, Isabel. Professores formadores: a relação entre a família, a escola e a aprendizagem.IN: Pais e professores disciplinadores são indispensáveis. Curitiba: Positivo, 2005, páginas 79 a 83.

SILVA, Juliano Correa da. Indisciplin escolar: a queixa da atualidade.Psicologia em estudo Maringá, v. 6, n. 1 jun. 2001.

TIBA, Içami. A indisciplina na escola IN: http://www.webartigos.com/artigos/a-indisciplina-na-salade-aula/44790/\#ixzz315tEWaoz Acesso: 08.05.2014.

Disciplina: Limite na medida certa. São Paulo: Editora Gente, 1996.

\section{Como citar este artigo (Formato ISO):}

SOUSA, Edilândia C.; DANTAS, Maria de Lurdes Q.; CARNEIRO, Rita E.de S. ALVES, Maria Aparecida O. Indisciplina na EREM - Barão de Exu-PE: Resolução de Conflito. Id on Line Revista de Psicologia, Julho de 2014, vol.8, n.23, p. 285-294. ISSN 1981-1179. 